\title{
Mini-review \\ Three-dimensional culture models for human viral diseases and antiviral drug development
}

\author{
Graciela Andrei* \\ Rega Institute for Medical Research, K.U. Leuven, Belgium \\ Received 17 February 2006; accepted 31 May 2006
}

Dedicated to Prof. Erik De Clercq on the occasion of reaching the status of Emeritus-Professor at the Katholieke Universiteit Leuven in September 2006.

\begin{abstract}
Researchers are recognizing the limitations of two-dimensional (2D) cell cultures, given the fact that they do not reproduce the morphology and biochemical features that the cells possess in the original tissue. As an alternative, the three-dimensional (3D) cell culture approach offers researchers the possibility to study cell growth and differentiation under conditions that more closely resemble the in vivo situation with regard to cell shape and cellular environment. Currently, 3D culture models are being employed in many areas of biomedical research because they offer a more realistic milieu than $2 \mathrm{D}$ cultures. The era of $2 \mathrm{D}$ culture techniques is moving towards a new epoch of culture systems in $3 \mathrm{D}$. The present review is focused on topics of research on 3D cell cultures in virology and their use in antiviral drug development.
\end{abstract}

(C) 2006 Elsevier B.V. All rights reserved.

Keywords: Three-dimensional culture models; Organotypic cultures; Antivirals

\section{Contents}

1. Introduction . . .

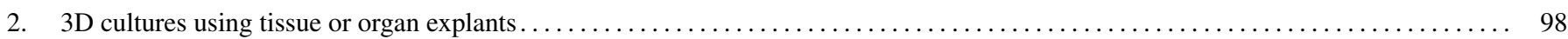

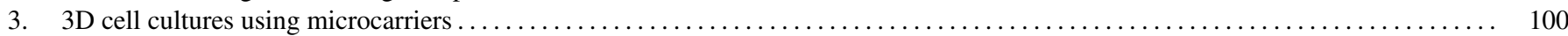

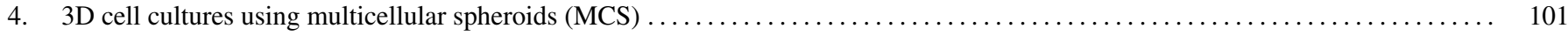

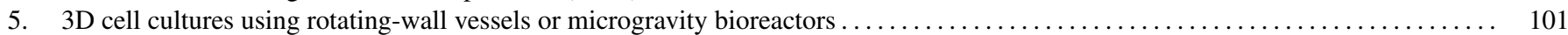

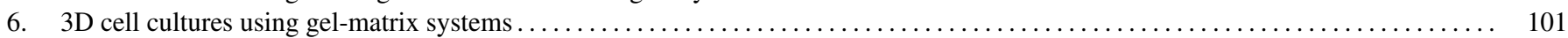

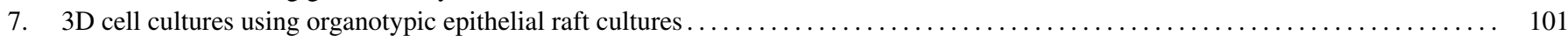

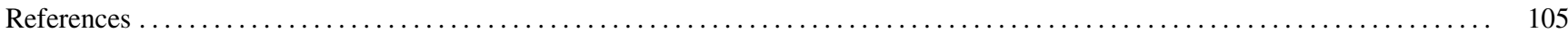

\section{Introduction}

In the early period of animal virus research, progress in simplifying the experimental systems came one step at the time: from initial studies with animals in the wild to laboratory animals (such as the mouse or the embryonated chicken eggs), then to the culture of tissues, and finally to the single cells in culture (Levine, 2001). Between 1948 and 1955, four important steps converted animal virology into a laboratory science: (i) Sanford

\footnotetext{
* Tel.: +32 163373 72; fax: +3216337340.

E-mail address: graciela.andrei@rega.kuleuven.ac.be.
}

et al. at the National Institute of Health (NIH) overcame the difficulty of culturing single cells, (ii) George Gey and his colleagues at John Hopkins Hospital cultured and passaged human cells for the first time and developed a line of cells (HeLa) derived from a cervical carcinoma, (iii) Harry Eagle at the NIH developed an optimum medium for culturing single cells, and (iv) in 1949, John Enders, Thomas Weller and Frederick Robbins found out that poliovirus could multiply in cultures of nonneuronal human cells; because of this discovery, the authors were awarded the Nobel Prize in physiology of medicine in 1954 (Levine, 2001). These revolutionary findings had two immediate effects in animal virology. First, they led to the development of the polio vaccine as the first vaccine produced in cell culture, and later 
to the production of other viral vaccines such as measles and rubella. Second, the use of cell culture for the study of viruses permitted studies of the biochemistry and molecular biology of viral replication beginning the modern era of molecular virology.

Cell culture is still the most common method used for the propagation of viruses. There are three main types of animal cell cultures: (i) primary cell cultures with a limited life span, usually not more than 5-20 cell divisions, (ii) diploid cell cultures, consisting of a homogeneous population of a single cell type, that can divide up to 100 times before dying and retain the diploid chromosome number despite the numerous cell divisions, and (iii) continuous cell lines which consist of a single cell type that can be propagated indefinitively; they are often abnormal in chromosome morphology and number (aneuploid) and can be tumorigenic. In these two-dimensional (2D) cultures the cells are grown either in suspension or as a monolayer.

Cultures of primary cells from different sources, including those from chicken embryos, and the kidneys of monkeys, dogs, rabbits and hamsters, have been used worldwide for the production of life and inactivated viral vaccines for human use for more than 40 years. Major success in the control of viral diseases, such as poliomyelitis, measles, mumps and rubella, were made possible through the use of vaccines prepared in primary cell cultures and experience have indicated that these products are safe and effective (WHO, 1998). However, in case alternative cell substrates are available, primary cell cultures are less likely to be used due to the fact that the quality and sensitivity of cultures obtained from different animals is variable; it will become increasingly difficult to obtain cultures derived from non-human primates and mostly, because contamination by infectious agents, such as viruses is a common problem.

The main advantage of diploid cell lines of human or monkey origin in comparison to primary cells is that they can be well characterized and standardized, and production can be based on a cell bank system. Vaccines prepared in two different diploid cell lines made from lung fetuses (e.g. WI-38 and MRC-5) have been extensively used for vaccine production over the past decades and the vaccines proved to be very safe. Diploid cell substrates have a finite capacity for serial propagation, which ends in senescence; they are non-tumorigenic and display diploid cytogenetic characteristics with a low frequency of chromosomal abnormalities of number and structure.
Continuous cell lines have the potential for an infinite life span and have been derived by the following methods: (a) serial subcultivation of a primary cell culture of a human or animal tumor, such as HeLa cells; (b) transformation of a normal cell having a finite life span with an oncogenic virus, for example, a B lymphocyte transformed by Epstein-Barr virus; (c) serial subcultivation of a normal cell population generating a new cell population having an infinite life span; (d) fusion between a myeloma cell and an antibody-producing B lymphocyte. Continuous cell lines are now considered to be suitable substrates for the production of many biological medicinal substances; a cell bank system similar to that used for the diploid cell lines provides a means for the production of biologicals for an indefinite period based on well characterized and standardized cells. Many of them express endogenous viruses and are tumorigenic; therefore, the risk of tumorigenicity associated with residual cellular DNA that may encode transforming proteins and growth-promoting proteins. WHO (World Health Organization) requirements for continuous cell lines used for biologicals production have been published (WHO, 1998).

Cell cultures have been used not only for the propagation of viruses and production of biologicals, such as vaccines, but also for studies of biochemistry and molecular biology of viral replication. Increasingly, researchers are recognizing the limitations of $2 \mathrm{D}$ cell cultures, given the fact that they do not reproduce the morphology and biochemical features that the cells possess in the original tissue. As an alternative, the three-dimensional (3D) cell culture approach offers researchers a means to study cell growth and differentiation under conditions that reproduce an in vivo environment. Holtfreter (1944) and later Moscona $(1952,1961)$ pioneered the field of 3D cell cultures by their systematic research on morphogenesis using spherical reaggregated cultures of embryonic or malignant cells. Subsequent studies by Sutherland (1988) and Sutherland et al. (1971) and associates enlarged considerably the spectrum of research on cell aggregates, by using multicellular tumor spheroids as an in vitro model for systematic studies on tumor cell response to therapy.

Although the importance of cellular context has been appreciated since a long time technical steps in 3D cell culture have not been introduced until relatively recently. The consequences of trying to extrapolate 2D findings into notions of cellular behavior in 3D are becoming clear (Edelman and Keefer, 2005). For

Table 1

Approaches commonly used to produce 3D cultures

\begin{tabular}{|c|c|}
\hline Type of culture & Properties \\
\hline Organotypic explant cultures & Whole organs or organ elements or slices are harvested and grown on a substrate in media \\
\hline Stationary or rotating microcarrier cultures & Dissociated cells aggregate around porous circular or cylindrical substrates with adhesive properties \\
\hline Multicellular spheroid (MCS) cultures & $\begin{array}{l}\text { Spheroids are grown in recipients with a non-adhesive surface, on which aggregates of isolated cells or small } \\
\text { explants derived from a tissue progressively round up and form spheres that can grow up to } 1 \mathrm{~mm} \text { in diameter }\end{array}$ \\
\hline Micromass cultures & Cells are pelleted and suspended in media containing appropriate amounts of nutrients and differentiation factors \\
\hline $\begin{array}{l}\text { Rotating wall vessels (RWVs) or } \\
\text { microgravity bioreactors }\end{array}$ & Free cells in a rotating vessel adhere to one another and eventually form tissue- or organ-like structures \\
\hline Gel-matrix systems & $\begin{array}{l}\text { Cells are embedded in a substrate, such as agarose or matrigel, that may or may not contain a scaffolding of } \\
\text { collagen or other organic or synthetic fiber which mimics the cell-extracellular matrix (ECM) }\end{array}$ \\
\hline Organotypic epithelial raft cultures & $\begin{array}{l}\text { Epithelial cells are placed on top of a dermal equivalent and then raised at the air-liquid interface to allow full } \\
\text { differentiation }\end{array}$ \\
\hline
\end{tabular}


example, insights into the differences in properties of cells in $2 \mathrm{D}$ versus $3 \mathrm{D}$ cell cultures were made by cancer researchers who showed the reversion of the malignant phenotype of human breast cells in $3 \mathrm{D}$ cultures and in vivo by $\beta 1$-integrin blocking antibodies (Weaver et al., 1997). This effect was not reproducible in $2 \mathrm{D}$ cell cultures. Later studies have shown that environmental conditions have important effects on the neoplastic properties of tumor cells, and such effects may influence the pharmacological responses of cancer cells to chemotherapeutic drugs (Sahai and Marshall, 2003).

One major advantage of 3D cell cultures is their well-defined geometry and in comparison with conventional cultures, they more closely resemble the in vivo situation with regard to cell shape and cellular environment, and shape and environment can determine gene expression and the biological behavior of cells (Mueller-Klieser, 1997). Different approaches have been employed to produce 3D cultures (Table 1). At present, research on $3 \mathrm{D}$ cell systems is more vital and productive than ever, the potential of 3D cell cultures being exploited in many areas of biomedical research. The present review is focused on topics of research on 3D cell cultures in virology and their use in the development of antiviral chemotherapeutics.

\section{3D cultures using tissue or organ explants}

Various biological tissues can be kept as explants in tissue or organ culture, maintaining cellular function for a limited period of time.

The development of organ cultures with human mucosal tissues has provided some insight into human immunodeficiency virus (HIV-1) infection and transmission across the mucosal barrier. Collins et al. (2000) reported an organ culture model, derived from squamous cervical tissue, showing transmission of HIV-1 to cells of the female genital tract. In this organ culture model a piece of squamous cervical tissue with the epithelium layer oriented on top was placed in the top chamber on a $3.0 \mu \mathrm{m}$ filter in a Transwell, with the area surrounding the tissue sealed with agarose (Fig. 1). A Transwell with agarose only in the top chamber served as a negative control, whereas a Transwell with a $3.0 \mu \mathrm{m}$ membrane only served as a positive control for virus transmission. At various days following addition of cell-associated or cell-free virus, HIV-1 transmission across the mucosa was determined by measuring HIV-1 in the bottom chambers using an infectivity assay in cMAGI cells (Kimpton and Emerman, 1992; Sista et al., 2004). The percentage of virus transmission in the tissue-containing well was compared with the amount of virus transmitted through the membrane in the control well containing medium alone (Fig. 1). The $3.0 \mu \mathrm{m}$ membrane in the Transwell allowed the passage of virus, but not the infected cells, into the bottom chambers. The authors reported that transmission of a cell-free T-cell-tropic (Ttropic) HIV-1 isolate, like that of a cell-free macrophage-tropic (M-tropic) HIV-1 isolate, was highest within $24 \mathrm{~h}$. Lack of transmission of HIV-1 inactivated by ultraviolet irradiation indicated the specificity of HIV-1 transmission in this organ culture model. As this model used tissues rather than a monolayer of cells (primary or transformed), it provided the natural tissue architecture, including epithelial cells, submucosa and immune cells, such as $\mathrm{T}$ cells, macrophages and Langerhans cells (LCs). Viral RNA was detected mostly in memory CD4+ T cells located immediately beneath the epithelial layer. Viral RNA signal was also detected, to a lesser extent, in scattered CD14+ macrophages.
Infection with cell associated or cell-free HIV-1

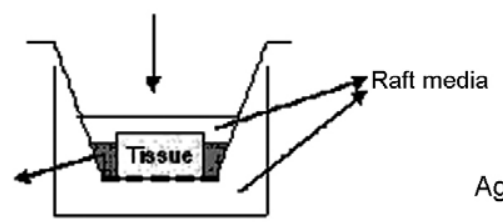

(A)

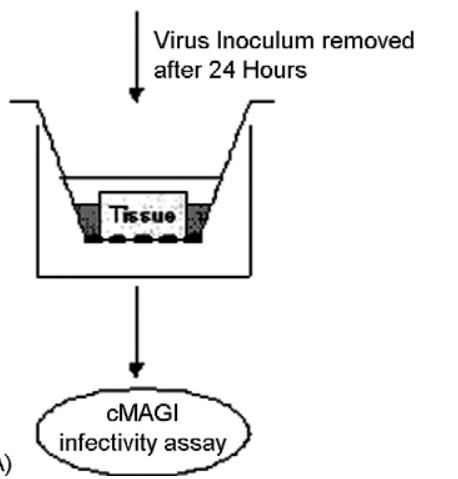

Infection with cell associated or cell-free HIV-1

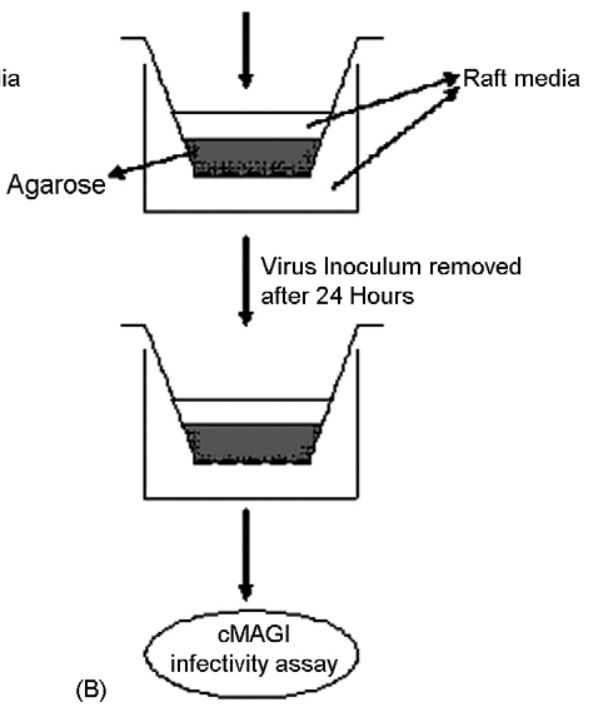

Infection with cell associated or cell-free HIV-1

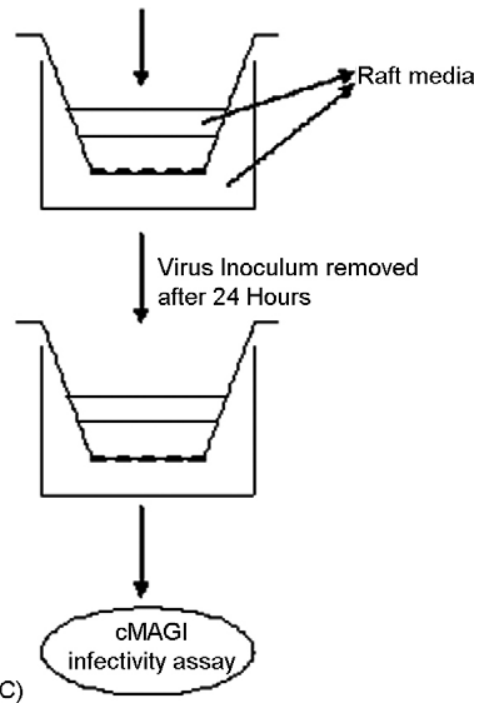

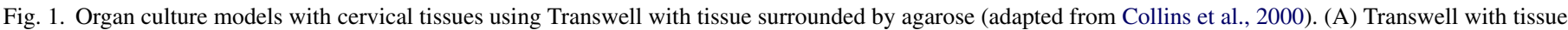

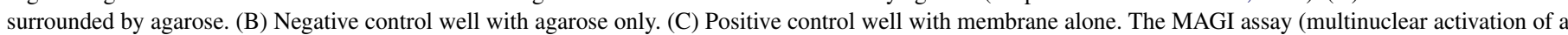

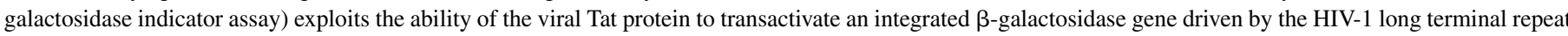

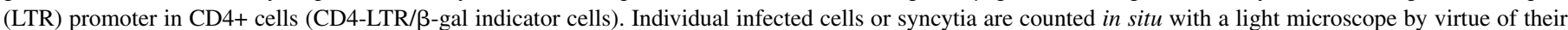

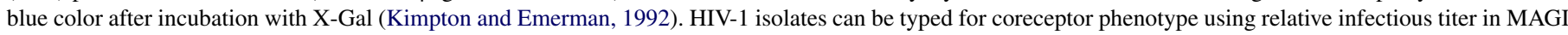
cells (expresses CXCR4) vs. cMAGI cells (expresses CXCR4 and CCR5) (Sista et al., 2004). 


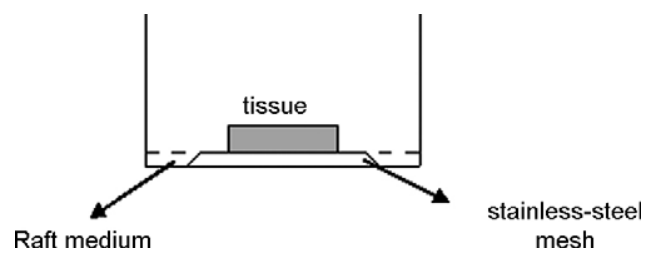

Fig. 2. Organ culture models with cervical tissues using tissue grown on stainless-steel mesh.

The same year, Greenhead and collaborators, also found that the target cells for HIV-1 infection in the cervical mucosal tissue were found directly below genital epithelium, suggesting that HIV must cross this barrier to establish infection (Greenhead et al., 2000). Moreover, dual immunohistochemistry identified the majority of HIV-infected cells as macrophages. In these studies, cervical and vaginal explants, comprising both epithelial and stromal tissue, were cultured on squares of stainless-steel mesh, individually, so that a meniscus of culture medium was in contact with the under surface of the grid (Fig. 2). Genital epithelial cells were not susceptible to HIV infection and appeared to play no part in the transfer of infectious virus across the epithelium, suggesting that intact normal cervical and vaginal epithelial cells, in the absence of inflammatory stimuli, provide a barrier for HIV-1 (Greenhead et al., 2000). Thus, transmission of HIV infection at such tissue sites is likely enhanced by any physical breach in epithelial integrity, caused by physical abrasion, ulceration, or inflammation. Immune activation (treatment with phytohemaglutinin and IL-2) of ectocervical, endocervical and vaginal explants enhanced HIV infection. This observation suggests that transmission and productive infection of genital mucosa are likely to be enhanced by concomitant immune activation in vivo. Thus, infection with sexually transmitted diseases (STDs) resulting in local inflammation, and activation of local inflammatory cells renders an individual more susceptible to HIV infection. This is in agreement with epidemiological data showing a correlation between STDs and HIV infection (Grosskurth et al., 1995; Miller, 1998) and an association between STDs and increased CD4 levels and coreceptor expression in genital mucosa (Levine et al., 1998; Patterson et al., 1998). The localization of cells expressing HIV-1 immediately below the epithelial layer is in keeping with findings reported in the macaque model. In this model, it was demonstrated that following vaginal transmission of either HIV-1 or simian immunodeficiency virus (SIV), infection was exclusively restricted to subepithelial cells (Miller et al., 1992; Nuovo et al., 1993; Pomerantz et al., 1988).

The model of HIV-1 infection described by Greenhead and colleagues (2000) appeared to be suitable for the evaluation of potential virucidal agents. Experiments using a panel of virucidal agents demonstrated differential efficiency to block HIV-1 infection of subepithelial cells from partial to complete inhibition. Nonoxynol-9 (N-9; a nonionic surfactant known to be active against HIV-1 and other sexually transmitted diseases) and gramicidin (GD; a peptide antibiotic with virucidal activity) did not provide complete protection from HIV-1 infection in the cervical tissue at non-toxic concentrations, while PRO 2000 (a naphthalene sulfonate polymer that appears to disrupt the initial binding and fusion events of HIV-1 infection) efficiently blocked HIV infection of cervical tissue under conditions which mimic both compromised epithelial integrity and inflammatory conditions (Greenhead et al., 2000).

Studies analyzing cervical biopsies have shown that CCR5, the predominat coreceptor for M-tropic HIV-1 isolates, is the major HIV coreceptor expressed in the female genital tract and CXCR4, the coreceptor for T-tropic HIV-1 isolates, is the predominantly expressed HIV-1 coreceptor in peripheral blood (Patterson et al., 1998). Patterson et al. (2002) used explants from foreskin tissue and cervical biopsies (Fig. 1A) to assess the proportion of all cells that are the major target cells for HIV1, i.e. CD4+ T cells, macrophages, and LCs, the expression of the chemokine receptors (CCR5 and CXCR4) and the infectability of these target cells with HIV-1. Foreskin and cervical biopsies were infected ex vivo in organotypic culture with HIV and the HIV-1 RNA copies in foreskin and cervical mucosal tissue were compared. Foreskin mucosa contained higher mean proportions of CD4+ T cells (22.4\%), macrophages $(2.4 \%)$ and LCs $(11.5 \%)$ in adults than in children $(4.9 \%, 0.3 \%$, and $6.2 \%$, respectively) or in cervical mucosa $(6.2 \%, 1.4 \%$, and $1.5 \%$, respectively). Foreskin immune cells expressed predominantly the CCR5 HIV-1 coreceptor and furthermore, adult foreskin mucosa was found to have a greater susceptibility to infection with a homogeneous M-tropic isolate of HIV-1 than cervical mucosa or the external surface of foreskin tissue. According to these findings it appears that circumcision likely reduces risk of HIV-1 acquisition in men by decreasing HIV-1 target cells, supporting observational epidemiological studies reporting a significant association between lack of male circumcision and HIV-1 acquisition (Bailey et al., 2001; Weiss et al., 2000).

In a later work, Patterson's group (Gupta et al., 2002) by using the in situ hybridization assay for HIV-1 RNA in the cervical organ culture system determined that memory CD4+ $\mathrm{T}$ cells and not LCs were the first cells that became infected during HIV-1 transmission across the cervical mucosa $6 \mathrm{~h}$ after virus exposure. At $96 \mathrm{~h}$ post-inoculation, in addition to memory CD4+ T cells, infected LCs and macrophages were also detected. When the effects of viral phenotypes on HIV-1 transmission across the mucosa were examined, significant levels of transmission of both R5 (isolates using CCR5) and X4 (isolates using CXCR4) HIV-1 were demonstrated, although the transmission efficiency was higher from the cell-free R5 virus. These data suggested that at least in women there is no preferential transmission of M-tropic HIV-1, although there could be a difference in transmission efficiency between strains of HIV-1 with different phenotypic properties. This hypothesis was supported by the data obtained in a study performed in Kenya, where it was found that women from Kenya were often infected with multiple virus variants, whereas men from Kenya were not (Long et al., 2000). Moreover, a heterogeneous virus was present in women before their seroconversion, indicating that diversity was most likely to be the result of transmission of multiple variants. These findings indicated that there are important differences in the transmitted virus population in women and men, even when cohorts from the same geographic 
region who are infected with the same subtypes of HIV-1 are compared.

Some of these studies that used human organ culture techniques to document the physical transfer of HIV-1 virions across epithelial surfaces drew criticism because of possible virion leakage around the tissue pieces. Maher et al. (2005) developed human cervicovaginal organ culture systems to examine the initiating events in HIV-1 transmission after exposure to various sources of HIV-1 infectivity, including semen and their investigations were focused on the detection of individual HIV-1 infected cells and direct visualization of bound virions and cells at and beneath the exposed mucosal surfaces. Newly infected cells could be detected in the cervical submucosa 3-4 days after exposure to a primary HIV-1 isolate. At earlier times extensive and stable binding occurred when the cervical surfaces were exposed to virions or seminal cells and virions could actually penetrate beneath the epithelial surface, confirming previous observations.

$\mathrm{Hu}$ et al. (2004) evaluated HIV-1 attachment and entry inhibitors for their ability to prevent infection of, and dissemination from, human cervical tissue ex vivo. Cervical explants were incubated before infection with inhibitors specific for CD4 (anti-CD4 mAb RPA-T4), CCR5 (TAK-779), CCR5 and CCR3 (AOP-RANTES), and CXCR4 (AMD3100). The authors demonstrated that blockade of the primary receptors for HIV-1 infection, CD4 or CCR5 or/and CXCR4, was sufficient to inhibit localized HIV-1 infection of human cervical tissue, suggesting that CCR5 and CXCR4 are the predominant coreceptors for HIV infection of cervix in vivo. However, inhibition of HIV-1 uptake and subsequent transmission to $\mathrm{T}$ lymphocytes by migratory cells required blockade of both CD4 and mannose-binding Ctype lectin receptors including dendritic cell-specific intercellular adhesion molecule-grabbing integrin (DC-SIGN). Two major populations of migratory cells were identified: CD3+HLA-DRand CD3-HLA-DR+ cells, the latter accounted for as much as 90\% of HIV-1 dissemination and expressed also DC-SIGN. DCs have been proposed to be targets of HIV during transmission (Pope, 1999). After infection or the attachment to DCs via DCSIGN, they migrate to the draining lymph node and are thought to transmit the virus to helper $\mathrm{T}$ cells during antigen presentation (Geijtenbeek et al., 2000). Therefore, strategies aimed at blockade of HIV-1 uptake by cells within genital mucosa should target both localized infection and dissemination pathways and the ex vivo organ culture model may provide a frame of reference for future evaluation of microbicides. Two important points concluded from studies using the organ cultures should guide the formulation of new microbicides: (i) there are multiple ways by which HIV-1 can infect target cells in the genital mucosa and thus, a successful host-target microbicide formulation will have to block all the potential pathways of HIV entry and (ii) even if all host receptors for viral entry are blocked, HIV may be capable of evading these inhibitors by hitching a ride on DCs, allowing the virus to remain in an infectious state long enough to reach areas where the microbicides do not penetrate (Davis and Doms, 2004).

Different reports documented the ability of the nonnucleoside reverse transcriptase inhibitor (NNRT) UC-781 to block both direct HIV-1 infection of human explants and dissemination of virus by migratory cells (Gupta et al., 2002; Zussman et al., 2003; Fletcher et al., 2005). In contrast with other NNRT inhibitors, UC-781 has great potential to serve as a microbicide. The main reason is that UC-781 is a tight-binding inhibitor, the only so far described for HIV-1 RT. UC-781 binds very rapidly to HIV-1 RT, with very high affinity and does not readily dissociate from the enzyme. This property confers to UC-781 the potential to be a 'topical' barrier for HIV transmission. Exposure of the cervical explants to a topical formulation of UC-781 resulted in blocking of subsequent HIV-1 viral infection of mucosal tissue and transinfection mediated by migratory cells without toxicity, indicating that UC-781 may be a good candidate microbicide. PMPA \{9-[2-(phosphonomethoxy)propyl]adenine $\}$, a nucleotide analogue that blocks viral replication by inhibiting reverse transcriptase, was also shown to be able to inhibit viral transmission across the mucosa (Gupta et al., 2002). These findings support the utility of organ cultures with human mucosal tissues to screen topical microbicides for their ability to block sexual transmission of HIV-1.

\section{3D cell cultures using microcarriers}

As a strategy to improve the production of some viral vaccines, large-scale cultivation of Vero cells in microcarrier cultures has been used. Today, Vero cells are considered as a suitable substrate for the production of viral vaccines, and this cell line presents advantages over primary and diploid cell substrates (Kumar et al., 2002). Vero cells can be used in microcarrier and suspension cultures for large scale production in bioreactors and the production of virus titers achieved in these culture systems is higher (Montagnon et al., 1981; Duchene et al., 1990). These properties facilitate the transfer of vaccine production to developing countries, which is an important goal of the WHO. Vero cells have been shown to be free of oncogenic property and they do not present any threat to human health when used as a substrate for biological production (Vincent-Falquet et al., 1989; Horaud, 1992; Montagnon and Vincent-Falquet, 1998). Therefore, Vero cells have been accepted for vaccine production by the WHO and are currently used in the manufacture of rabies (Montagnon, 1989), polio (Montagnon, 1985) and Japanese encephalitis (Sugawara et al., 2002) vaccines. The optimization of virus yield as a strategy to improve viral vaccine production by Vero cells in microcarrier cultures (in spinner flasks or in a bioreactor) is documented by several reports (Montagnon et al., 1983; Sugawara et al., 2002; Yokomizo et al., 2004; Trabelsi et al., 2006).

In one of the many attempts that have been made to culture hepatitis C virus (HCV) in vitro, Aizaki et al. (2003) reported the production and release of infectious $\mathrm{HCV}$ from human liver cell cultures in a 3D radial-flow bioreactor, in which human liver cells retained their differentiated hepatocyte functions and morphological appearance for an extended period of time. This system consists of a vertically extended cylindrical matrix comprised of porous glass bead microcarriers through which liquid medium flows and the cells solidly attached on the surfaces and within the pores of the microcarriers in highly dense colonies 
(Kawada et al., 1998). When human liver cells (FLC4 cells derived from the cloning of JHH4 cells) grown in a 3D radialflow bioreactor were transfected with full-length HCV RNA or inoculated with infectious serum, propagation of $\mathrm{HCV}$ could be shown, although the titers were not high (Aizaki et al., 2003). Furthermore, infectious virus was released into the supernatant in the absence of obvious cell lysis.

\section{3D cell cultures using multicellular spheroids (MCS)}

Multicellular spheroids (MCS) have gained experimental importance as a model of tumors; they can be grown from cell lines or can be derived from primary tumors. The complex tissue architecture present in the tumors (that is, tumor cells, connective tissue, immune cells, capillaries, and non-cellular constituents) is present in the organotypic spheroids grown from primary tumors. Therefore, these cultures resemble the situation in vivo more closely than tumor cell lines, with the advantage that tumor cells remained in their original microenvironment without any process of in vitro selection.

The use of adenovirus for gene transfer and as an oncolytic agent has gained importance in the last years. As adenovirus distribution and spread cannot be studied in 2D cell cultures, a 3D model mimicking the in vivo biology of tumors, like the MCS, is required. Grill et al. (2002) studied adenovirus replication and penetration in tumor spheroids grown from primary brain tumor material using $\beta$-galactosidase and luciferase reporter genes expressed by adenoviruses. Infection with a replication-defective adenovirus was restricted to the first layer of cells, while transgene expression and viral spreading deep in the 3D structure took place when spheroids were infected with a replication-competent adenovirus. The authors demonstrated that the oncolytic activity of replication-competent adenoviruses in the MCS could be evaluated using a tetrazoliumbased metabolic assay.

The importance of performing studies using multicellular spheroids was recently confirmed by Finocchiaro et al. (2004), who reported the efficacy of the herpes simplex thymidine kinase/ganciclovir (HSV $t k / G C V$ ) suicide system using HSV $t k$ expressing cells assembled as MCS. HSVtk-expressing cells grown as MCS manifested a lower GCV cytotoxicity and bystander effect compared to the same cells grown as monolayers, although HSV $t k$-expressing cells in $2 \mathrm{D}$ or $3 \mathrm{D}$ cultures were always significantly more sensitive to GCV than the $\beta$ galactosidase counterparts, supporting the feasibility of this suicide approach in vivo.

\section{3D cell cultures using rotating-wall vessels or microgravity bioreactors}

Cells grown in rotating-wall vessels (RWVs) are subjected to low shear motion, and the replication of certain viruses such as rhinoviruses has been described to be enhanced by motion (Hughes, 1993). Long et al. (1998) reported rhinovirus replication in HeLa cell cultures under conditions of simulated microgravity, using RWVs. Rhinovirus replication was enhanced in cultures grown in the presence of motion (Teflon roller bottle cultures and RWV cultures). Additionally, multiple rounds of rhinovirus replication yielded more virus in simulated microgravity conditions. Viral transmission in cell cultures in RWVs was efficient and was similar to, or better than, what occurred in the Teflon roller bottles. The authors speculated that the cultivation of cells in simulated microgravity possibly affected the rate of viral adsorption/uptake, the viral replication cycle, and/or the viral yield, and concluded that RWVs provide an effective means for culturing human rhinoviruses.

Margolis et al. (1997) reported that the use of blocks of human lymphoid tissue cocultured with a suspension of tonsilar lymphocytes in a RWV culture system constitute a useful model for simulating normal lymphocyte recirculatory traffic and provide a new tool for testing the various aspects of HIV pathogenesis. Fragments of the surgically excised human lymphoid tissue remained viable for at least 3 weeks when cultured in the RWV system and such lymphoid tissue gradually showed a loss of both $\mathrm{T}$ and $\mathrm{B}$ cells to the surrounding growth medium. This cellular migration could be partially or completely inhibited by embedding the blocks of lymphoid tissue in either a collagen or agarose gel matrix, these embedded tissue blocks retaining most of the basic elements of a normal lymphoid cytoarchitecture. Both embedded and nonembedded RWV-cultured blocks of human lymphoid tissue were capable of productive infection by strains of HIV-1 with different tropism and phenotype, as demonstrated by an increase in both p24 antigen levels, free virus in the culture medium and HIV-1 RNA-positive cells inside the tissue.

\section{3D cell cultures using gel-matrix systems}

Although explants of tissue have been used for many years, considerable progress has been made more recently in generating bioartificial tissues in vitro from single cells of primary material or of cell lines. In the gel-based techniques, the cells are embedded in a substrate, such as agarose or matrigel that may or may not contain a scaffolding of collagen or other organic or synthetic fiber which mimics the cell-extracellular matrix (ECM). Three-dimensional growth in culture using gel-matrix systems has been demonstrated in diverse tissue types, including cardiac myocytes, osteoblasts, myoblasts, condrocytes, hepatocytes, cerebral microvascular endothelial cells, mesothelial and endothelial cells, odontoblasts, cortical neurons, astrocytes and neuronal progenitor cells (Edelman and Keefer, 2005).

So far, the use of gel-matrix systems in virology appears to be very limited. Recently, Thach and Stenger (2003) studied the effects of collagen matrix on Sindbis virus infection of baby hamster kidney (BHK) cells grown in 3D collagen gels. Using Sindbis virus carrying the green fluorescent protein gene, the virions were found to be capable of penetrating the 3D collagen matrix and infecting the cells.

\section{3D cell cultures using organotypic epithelial raft cultures}

Several techniques have been used to culture threedimensional epithelium in vitro. These efforts led to the 

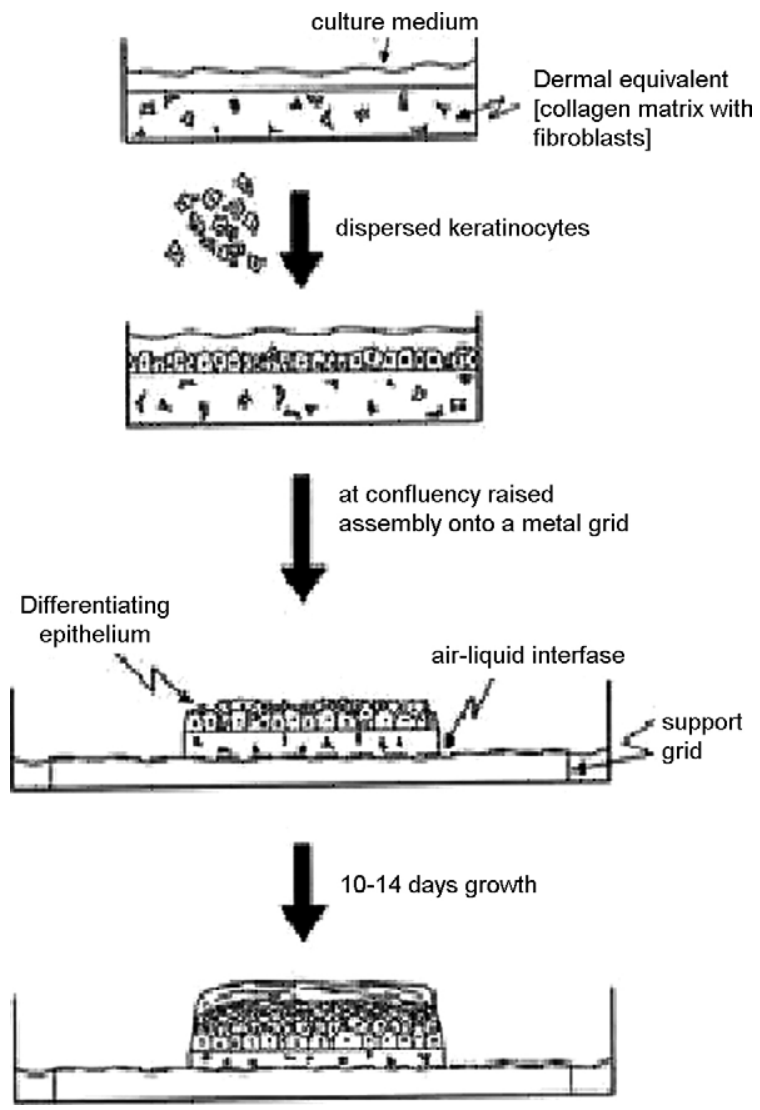

Fig. 3. Scheme showing the different steps used in the production of organotypic epithelial raft cultures. The epithelial cells are seeded on the top of the dermal equivalents collagen matrix with feeder cells and maintained submerged for 24-48 $\mathrm{h}$. The rafts are then lifted (day 0 ) and placed onto stainless steel grids at the air-liquid interface and feeded by the medium underneath and incubated for a period of 10-14 days. Epithelial cells stratify and differentiate into fullthickness tissue mimicking the in vivo situation. The rafts can be then harvested and examined by standard histological, molecular, and biochemical techniques.

development of the organotypic epithelial raft cultures, which permit full differentiation of the epithelial cells and accurately mimic the physiology of the epidermis. These cultures are constructed by placing the epithelial cells on top of a dermal equivalent and then raising the cells to the air-liquid interface (Fig. 3). The dermal equivalent is composed of natural dermal elements (collagen matrix with fibroblasts) or a synthetic dermal matrix maintained on a rigid support. Normal epithelial cells stratify and differentiate into full-thickness tissue mimicking the original tissue from which the particular keratinocytes were derived (Wilson et al., 1992; Chow and Broker, 1997) while cells derived from neoplasias exhibit in the raft cultures dysplastic morphologies similar to the (pre)neoplastic lesions seen in vivo (Regnier et al., 1988).

Many important human pathogens, including various viruses, target the epithelium during at least some part of their natural history. Pathogenic viruses use human epithelium as the initial site of infection, the site for replication, a staging area for transportation to other tissues, and a site for latency or persistence (Bodily et al., 2006). The 3D raft cultures allow the cells to undergo the authentic program of differentiation, providing a unique and essential tool for the study of differentiation-dependent biology of viruses and other pathogens.

Organotypic epithelial raft cultures have proven to be a breakthrough in the research on human papillomaviruses (HPV), since their life cycle is tightly linked to the differentiation of the host epithelial tissue. This link to differentiation hampered the study of the HPV life cycle for many years. The organotypic epithelial raft culture system, which mimics important morphological and physiological characteristics of the epithelium proved to be a valuable tool for studying HPV (Meyers et al., 1992, 1997, 2002; McLaughlin-Drubin et al., 2003, 2004; Fehrmann and Laimins, 2005). Applications of the organotypic culture systems to HPV-11 infected condylomatous tissue explants and to an immortalized human epithelial cell line that is derived from a cervical dysplasia and harbors episomal HPV-31b DNA have validated this culture system, in that progeny HPV virions were produced for the first time in vitro (Dollard et al., 1992; Meyers et al., 1992).

HPV-containing cells that are either derived from biopsies or created by transfection of keratinocytes with HPV genomic DNA are used in this system, the organotypic cultures of HPVimmortalized keratinocytes resembling to different grades of neoplasia as seen in vivo (Hurlin et al., 1991; Blanton et al., 1991; Steenbergen et al., 1998). These cell lines grown in raft cultures allow the study of all stages of the HPV life cycle, including episomal maintenance of the viral genome, amplification of the viral genome, differentiation-dependent viral gene expression and virion morphogenesis. A detailed review of the use of organotypic raft cultures for the study of the natural history of HPV has been recently published (Bodily et al., 2006).

A small number of studies have used organotypic cultures to examine the interaction of infected keratinocytes with cells and factors of the immune system. Organotypic cultures of HPVtransformed keratinocytes have been proposed as a convenient model for studying the ability of allogeneic peripheral blood mononuclear cells (PBMCs) to migrate in a (pre)neoplastic epithelium (Jacobs et al., 1998; Delvenne et al., 2001). Most of the infiltrating cells were $T$ cells and a small number of natural killer cells. Also, DCs were shown to be able to infiltrate raft cultures and differentiate (Hubert et al., 1999).

So far, published data concerning the use of raft cultures for testing the efficacy of therapeutic interventions for HPV appears to be rather limited, mostly due to the difficulty in setting an endpoint for activity and in proving the selectivity of the agents. Most of the reports are based on morphological alterations of the rafts observed following treatment with the different agents without quantification of the antiviral effects. In general, treatment of dysplastic raft tissue with retinoic acid, interferon-gamma (INF- $\gamma$ ) and tumor necrosis alpha (TNF- $\alpha$ ) appeared to induce a less dysplastic, more normal differentiation program (Yokoyama et al., 2001, Delvenne et al., 2001). Similar results were obtained when cervical intraepithelial neoplasia (CIN) grades I and III and invasive carcinoma raft cultures were treated with tumor growth factor $\beta$ (TGF- $\beta$ ) (Ozbun and Meyers, 1996). Sen et al. (2004) tested the effects of two commercially available IFNs, interferon- $\alpha-n 3$ and interferon- $\alpha-2 b$, on vegetative HPV replication in raft cultures able to sustain the 
complete viral life cycle of HPV 16, 18, and 31b. These studies showed that the two IFNs differed in their ability to affect viral load of the different HPV types. This is in keeping with studies using monolayer cultures to determine the efficacy of INF therapy for the treatment of cervical cancer where the results were inconsistent with controversial conclusions.

Based on the fact that expression of EGF receptor (EGFR) was abundant throughout the thickness of the epithelium of HPVpositive rafts and it was less expressed only in the basal layer of rafts of normal cervical keratinocytes, Renard et al. (2002) tested bispecific antibodies, which bind both the EGFR and CD3 in the raft culture model. These antibodies facilitated the infiltration of $\mathrm{T}$ cells into carcinoma rafts and increased killing of the HPV-positive cells by the lymphocytes, while they had no effect on T cell infiltration into rafts of normal keratinocytes. On the contrary, Mason et al. (1999) could not demonstrate an effect of Vitamin E in the raft culture model since little difference between vitamin-treated and control cultures, except for a reduction in the number of layers in the vitamin-treated cultures, were observed.

The major tea polyphenol, (-)-epigallocatechin (EGCG) was shown to decrease the thickness of rafts of both HPVimmortalized and HPV-transformed cells and to inhibit telomerase activity regardless of the cell type used (Yokoyama et al., 2004). However, induction of apoptosis following EGCG treatment was detected in raft cultures grown from HPV-18 immortalized cells but not from HPV-18 transformed cells. The adverse effects of microbicides (i.e. nonoxinol 9 , benzalkonium chloride, chlorhexidine and cholic acid) have also been evaluated in the raft culture model (Aebischer and McDougall, 1997). Following repeated treatment of rafts from normal keratinocytes and HPV-immortalized cells, harmful effects (histological alterations) were seen, while no alterations were observed in undifferentiated monolayer culture models.

HIV-1 infection of LCs in a reconstructed vaginal mucosa has been recently reported (Sivard et al., 2004). The reconstituted mucosa included two cell types (LCs and vaginal keratinocytes) and a submucosa (a de-epidermized dermis). Infection of LCs could be inhibited by the use of azidothymidine (AZT) and in addition, HIV-1 infected LCs of the reconstituted mucosa were able to transmit R5 or X4 HIV-1 strains to activated peripheral blood mononuclear cells.

Organotypic epithelial raft cultures have also been successfully applied to the study of herpes simplex virus (HSV) infection (Syrjanen et al., 1996; Visalli et al., 1997; Hukkanen et al., 1999; Meyers et al., 2003). In these studies a productive HSV1 infection was established with morphological characteristics of herpes lesions in vivo. However, differences in virus spread and the course of infection were observed among these studies. Syrjanen et al. (1996) and Hukkanen et al. (1999) obtained HSV1 infection throughout the whole epithelium only when the cells were infected before lifting, whereas Visalli et al. (1997) found a productive infection with HSV-1 in the basal and parabasal cells of the epithelium. The latter group used foreskin and cervical keratinocytes as the source of epithelial cells and mouse 3T3 cells as feeders, while Syrjanen et al. (1996) and Hukkanen et al. (1999) used a spontaneous transformed HaCaT keratinocyte cell line as the source of epithelial cells. Also, Visalli's group infected a fully stratified and differentiated organotypic culture tissue.

Meyers et al. (2003) found that HSV infection was able to induce significant cytopathic effects in HPV positive raft cultures and interestingly, HPV genome copy numbers were maintained in steady amounts during HSV-induced cytopathogenicity.

In the last years, we have reported the feasibility of using organotypic epithelial raft cultures of human keratinocytes as a model to evaluate both replication of poxviruses and $\alpha$ herpesviruses and efficacy of antiviral agents (Snoeck et al., 2002; Andrei et al., 2005; Dal Pozzo et al., 2005). As keratinocytes are one of the main target cells for productive infection of both poxviruses and $\alpha$-herpesviruses, characterization of virus replication in organotypic raft cultures of these cells represent a relevant model for studying virus-host cell interactions and antiviral agents. In our studies we have used normal keratinocytes derived from human neonatal foreskins and 3T3 mouse fibroblasts as feeder cells, and we could show that infection at different stages of differentiation with either HSV-1 or HSV-2, as well as with vaccinia virus (VACV) and cowpox virus (CPV) on the surface of the lifted epithelium occurs throughout the different layers of the epithelium (Fig. 4). Typical cytopathic changes identical to those found in the squamous epithelium in vivo were observed. Infection of organotypic raft cultures with varicella-zoster virus (VZV) appeared to depend on the stage of differentiation of the rafts, i.e. with the time the rafts were lifted to induce differentiation (Fig. 4). The discrepancies between the studies that have used HSV in organotypic epithelial raft cultures may be due to the type of murine fibroblasts used as feeders, the degree of maturation and proliferation of the epithelium produced, and the viral inoculum used for the viral infection.

In addition, we have demonstrated that the 3D epithelial raft culture represents a novel model for the study of antiviral agents against poxviruses and $\alpha$-herpesviruses. The activity of reference antiviral compounds was evaluated in this system by histological examination of the viral-induced cytodestructive effects and quantified by measuring viral titers and/or viral DNA load (Snoeck et al., 2002; Andrei et al., 2005). A correlation between the degree of protection as determined by histological examination and viral quantification could be demonstrated. Since no animal model is available for the evaluation of antiviral agents against VZV, the organotypic cultures may be considered a model to evaluate the efficacy of new anti-VZV antivirals before clinical trials. Furthermore, we showed that the 3D epithelial raft culture system could be also applied for the study of animal viruses, like the parapox orf virus, using epithelial cells isolated from the natural host, in this case lamb keratinocytes (Fig. 4) (Dal Pozzo et al., 2005).

Studies regarding the viral life cycle of adenovirus in stratified epithelia have been recently performed due to the potential employment of replication-competent adenoviruses as oncolytic agents in clinic, especially with neoplasias of epithelial origin. Using the raft culture system it was possible to study differentiation dependency of some of the early promoters of adenovirus (Noya et al., 2003). The effects of deletions of specific 

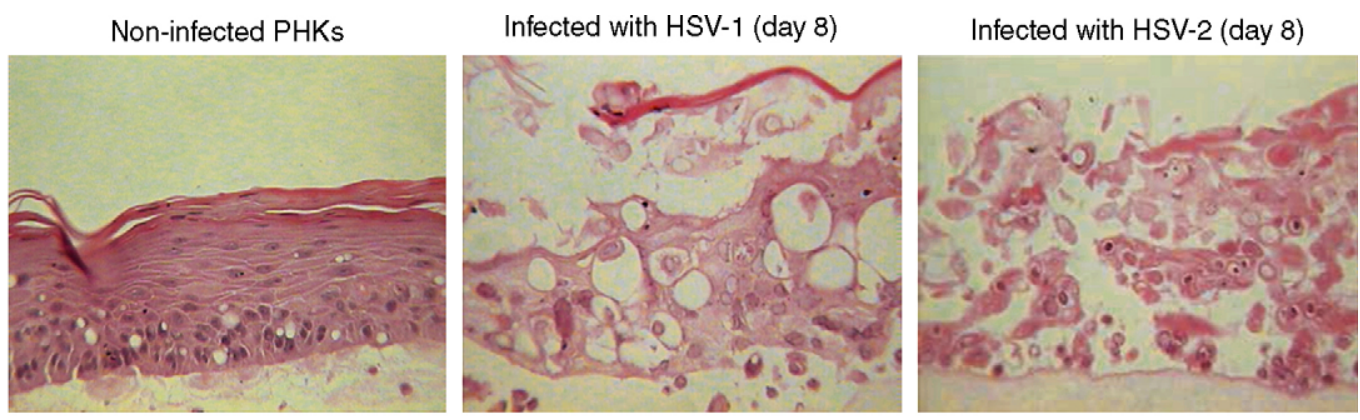

(A)
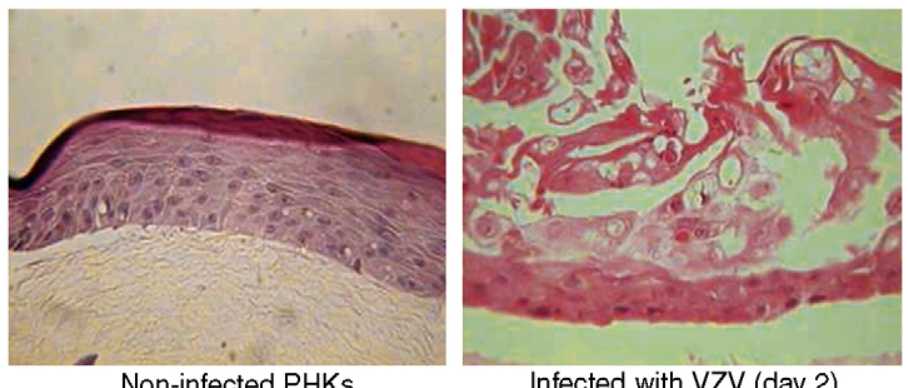

Infected with VZV (day 2)

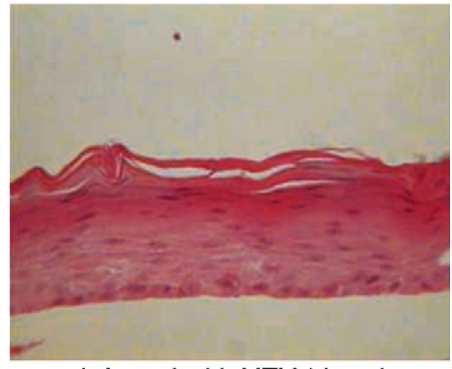

Non-infected PHKs
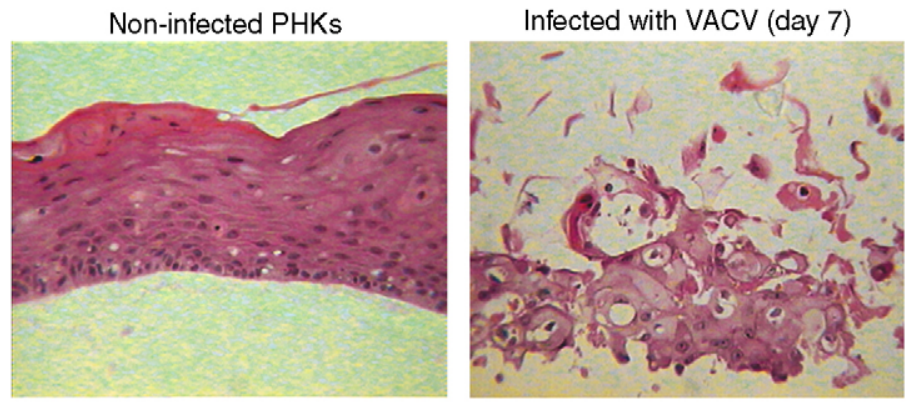

Infected with VZV (day 8)

Infected with CPV (day 7)

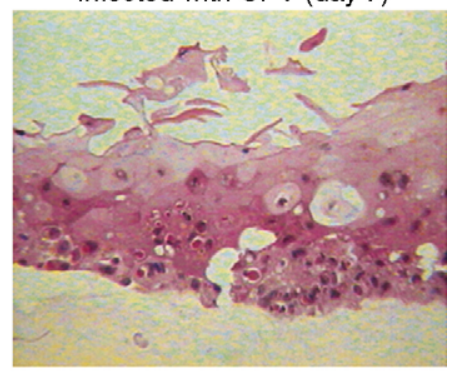

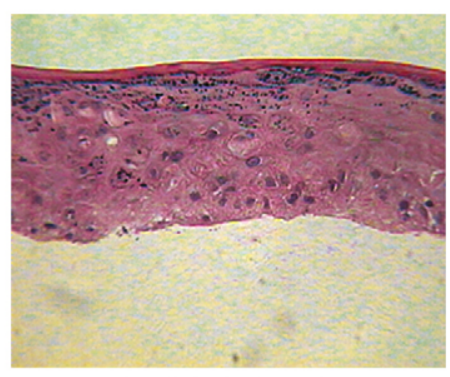

Non-infected PLKs

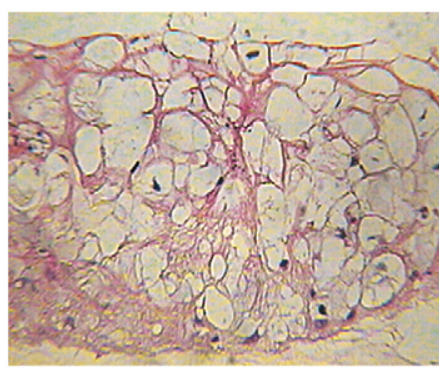

Infected with orf virus (day 6)

(B)

Fig. 4. (a) Pattern of herpesvirus infection in organotypic cultures of primary human keratinocytes (PHKs) infected with herpes simplex virus type 1 (HSV-1) or type 2 (HSV-2) at 8 days after lifting, and with varicella-zoster virus (VZV) at 2 or 8 days after lifting. (b) Pattern of poxvirus [vaccinia virus (VACV) and cowpox virus (CPV)] and parapoxvirus (orf virus) infection in, respectively, organotypic cultures of PHKs or primary lamb keratinocytes (PLKs) infected after 7 or 6 days after lifting. Magnification $40 \times$.

domains of adenovirus E1A protein in replication competent adenoviruses on their ability to selectively target and kill keratinocytes expressing the HPV-18 oncogenes E6 and E7 has been also reported (Balague et al., 2001).

The efficacy of using the differentiating epithelial tissue system to provide a proper environment for the complete life cycle of the adeno-associated virus type 2 (AAV) has also been shown (Meyers et al., 2000). AAV is a small, single-stranded DNA virus of the parvovirus family that requires the host cells to be co-infected with another virus type (helper, usually members of the adenovirus and herpes virus families) for productive replication. However, when primary foreskin keratinocyte monolayers grown on collagen matrices were infected with AAV while still submerged in medium and then raised to the air-liquid interface (to allow grow and differentiation into epithelial tissue), AAV underwent its complete life cycle without a helper virus. AAV progeny production correlated with epithelial differentiation, as non-differentiating keratinocytes were not able to support AAV replication devoid of a helper virus (Meyers et al., 2000). Viral particles were detected in the granular layers of the raft epithelium by electron microscopy and additionally, histological changes, some of which might be interpreted as cytopathology, were induced in the AAV-infected epithelial tissues. These data suggest a new biological model for AAV: an epithelio-tropic 
autonomous parvovirus that can alter normal squamous differentiation.

In a recent report, Johnson et al. (2005) described the activation of Kaposi's sarcoma-associated herpesvirus (KSHV) lytic gene expression during epithelial differentiation in an organotypic raft culture model of epithelium using keratinocytes from human tonsils that produced a nonkeratinized stratified squamous oral epithelium. The activation of KSHV lytic-gene expression was examined by using a recombinant virus (rKSHV) that expresses the green fluorescent protein during latency from the cellular EF-1alpha promoter and the red fluorescent protein (RFP) during lytic replication from the viral early PAN promoter. Infection of keratinocytes with rKSHV resulted in a latent infection; however, when these keratinocytes differentiated into a multilayered epithelium, lytic cycle activation of the KSHV occurred, as evidenced by RFP expression, expression of late proteins and the production of infectious rKSHV at the epithelial surface. These findings demonstrate that KSHV lytic activation occurs as keratinocytes differentiate into a mature epithelium, and it may be responsible for the presence of infectious KSHV in saliva.

Although 3D cultures may be expensive and laborious, several examples here described demonstrated the utility of these systems for the study of virus-host interactions in a more realistic milieu than that provided by $2 \mathrm{D}$ cell cultures.

\section{References}

Aebischer, F., McDougall, J.K., 1997. Organotypic raft cultures for the in vitro evaluation of vaginal microbicidal agents. Microbicides have epithelium-specific effects when repeatedly added onto organotypic human keratinocyte cultures. Sex Transm. Dis. 24, 69-76.

Aizaki, H., Nagamori, S., Matsuda, M., Kawakami, H., Hashimoto, O., Ishiko, H., Kawada, M., Matsuura, T., Hasumura, S., Matsuura, Y., Suzuki, T., Miyamura, T., 2003. Production and release of infectious hepatitis C virus from human liver cell cultures in the three-dimensional radial-flow bioreactor. Virology 314, 16-25.

Andrei, G., Van Den, O.J., Fiten, P., Opdenakker, G., Wolf-Peeters, C., De Clercq, E., Snoeck, R., 2005. Organotypic epithelial raft cultures as a model for evaluating compounds against alphaherpesviruses. Antimicrob. Agents Chemother. 49, 4671-4680.

Bailey, R.C., Plummer, F.A., Moses, S., 2001. Male circumcision and HIV prevention: current knowledge and future research directions. Lancet Infect. Dis. 1, 223-231.

Balague, C., Noya, F., Alemany, R., Chow, L.T., Curiel, D.T., 2001. Human papillomavirus E6E7-mediated adenovirus cell killing: selectivity of mutant adenovirus replication in organotypic cultures of human keratinocytes. J. Virol. 75, 7602-7611.

Blanton, R.A., Perez-Reyes, N., Merrick, D.T., McDougall, J.K., 1991. Epithelial cells immortalized by human papillomaviruses have premalignant characteristics in organotypic culture. Am. J. Pathol. 138, 673-685.

Bodily, J.M., Alam, S., Chen, H., Meyers, C., 2006. Organotypic raft cultures and the study of the natural history of papillomavirus. In: Campo, M.S. (Ed.), Papillomavirus Research: From Natural History to Vaccines and Beyond. Caister Academic Press, Norfolk, pp. 145-173.

Chow, L.T., Broker, T.R., 1997. In vitro experimental systems for HPV: epithelial raft cultures for investigations of viral reproduction and pathogenesis and for genetic analyses of viral proteins and regulatory sequences. Clin. Dermatol. 15, 217-227.

Collins, K.B., Patterson, B.K., Naus, G.J., Landers, D.V., Gupta, P., 2000. Development of an in vitro organ culture model to study transmission of HIV-1 in the female genital tract. Nat. Med. 6, 475-479.
Dal Pozzo, F., Andrei, G., Holy, A., Van Den, O.J., Scagliarini, A., De Clercq, E., Snoeck, R., 2005. Activities of acyclic nucleoside phosphonates against Orf virus in human and ovine cell monolayers and organotypic ovine raft cultures. Antimicrob. Agents Chemother. 49, 4843-4852.

Davis, C.W., Doms, R.W., 2004. HIV transmission: closing all the doors. J. Exp. Med. 199, 1037-1040.

Delvenne, P., Hubert, P., Jacobs, N., Giannini, S.L., Havard, L., Renard, I., Saboulard, D., Boniver, J., 2001. The organotypic culture of HPVtransformed keratinocytes: an effective in vitro model for the development of new immunotherapeutic approaches for mucosal (pre)neoplastic lesions. Vaccine 19, 2557-2564.

Dollard, S.C., Wilson, J.L., Demeter, L.M., Bonnez, W., Reichamn, R.C., Broker, T.R., Chow, L.T., 1992. Production of human papillomavirus and modulation of the infectious program in epithelial raft cultures. Genes Dev 6, 1131-1142.

Duchene, M., Peetermans, J., D’Hondt, E., Harford, N., Fabry, L., Stephenne, J., 1990. Production of poliovirus vaccines: past, present, and future. Viral Immunol. 3, 243-272.

Edelman, D.B., Keefer, E.W., 2005. A cultural renaissance: in vitro cell biology embraces three-dimensional context. Exp. Neurol. 192, 1-6.

Fehrmann, F., Laimins, L.A., 2005. Human papillomavirus type 31 life cycle: methods for study using tissue culture models. Methods Mol. Biol. 292, 317-330.

Finocchiaro, L.M., Bumaschny, V.F., Karara, A.L., Fiszman, G.L., Casais, C.C., Glikin, G.C., 2004. Herpes simplex virus thymidine kinase/ganciclovir system in multicellular tumor spheroids. Cancer Gene Ther. 11, 333-345.

Fletcher, P., Kiselyeva, Y., Wallace, G., Romano, J., Griffin, G., Margolis, L., Shattock, R., 2005. The nonnucleoside reverse transcriptase inhibitor UC-781 inhibits human immunodeficiency virus type 1 infection of human cervical tissue and dissemination by migratory cells. J. Virol. 79, $11179-11186$.

Geijtenbeek, T.B., Kwon, D.S., Torensma, R., van Vliet, S.J., van Duijnhoven, G.C., Middel, J., Cornelissen, I.L., Nottet, H.S., KewalRamani, V.N., Littman, D.R., Figdor, C.G., van Kooyk, Y., 2000. DC-SIGN, a dendritic cell-specific HIV-1-binding protein that enhances trans-infection of T cells. Cell 100, 587-597.

Greenhead, P., Hayes, P., Watts, P.S., Laing, K.G., Griffin, G.E., Shattock, R.J., 2000. Parameters of human immunodeficiency virus infection of human cervical tissue and inhibition by vaginal virucides. J. Virol. 74, $5577-5586$

Grill, J., Lamfers, M.L., van Beusechem, V.W., Dirven, C.M., Pherai, D.S., Kater, M., van der, Valk, Vogels, R., Vandertop, W.P., Pinedo, H.M., Curiel, D.T., Gerritsen, W.R., 2002. The organotypic multicellular spheroid is a relevant three-dimensional model to study adenovirus replication and penetration in human tumors in vitro. Mol. Ther. 6, 609-614.

Grosskurth, H., Mosha, F., Todd, J., Mwijarubi, E., Klokke, A., Senkoro, K., Mayaud, P., Changalucha, J., Nicoll, A., ka-Gina, G., 1995. Impact of improved treatment of sexually transmitted diseases on HIV infection in rural Tanzania: randomised controlled trial. Lancet 346, 530-536.

Gupta, P., Collins, K.B., Ratner, D., Watkins, S., Naus, G.J., Landers, D.V., Patterson, B.K., 2002. Memory CD4(+) T cells are the earliest detectable human immunodeficiency virus type 1 (HIV-1)-infected cells in the female genital mucosal tissue during HIV-1 transmission in an organ culture system. J. Virol. 76, 9868-9876.

Holtfreter, J., 1944. A study of the mechanism of gastrulation. J. Exp. Zool. 95, 171-212.

Horaud, F., 1992. Absence of viral sequences in the WHO-Vero Cell Bank. A collaborative study. Dev. Biol. Stand. 76, 43-46.

Hu, Q., Frank, I., Williams, V., Santos, J.J., Watts, P., Griffin, G.E., Moore, J.P., Pope, M., Shattock, R.J., 2004. Blockade of attachment and fusion receptors inhibits HIV-1 infection of human cervical tissue. J. Exp. Med. 199, 1065-1075.

Hubert, P., van den, B.F., Giannini, S.L., Franzen-Detrooz, E., Boniver, J., Delvenne, P., 1999. Colonization of in vitro-formed cervical human papillomavirus- associated (pre)neoplastic lesions with dendritic cells: role of granulocyte/macrophage colony-stimulating factor. Am. J. Pathol. 154, $775-784$. 
Hughes, J.H., 1993. Physical and chemical methods for enhancing rapid detection of viruses and other agents. Clin. Microbiol. Rev. 6, 150-175.

Hukkanen, V., Mikola, H., Nykanen, M., Syrjanen, S., 1999. Herpes simplex virus type 1 infection has two separate modes of spread in threedimensional keratinocyte culture. J. Gen. Virol. 80 (Pt 8), 2149-2155.

Hurlin, P.J., Kaur, P., Smith, P.P., Perez-Reyes, N., Blanton, R.A., McDougall, J.K., 1991. Progression of human papillomavirus type 18-immortalized human keratinocytes to a malignant phenotype. Proc. Natl. Acad. Sci. U.S.A. $88,570-574$.

Jacobs, N., Moutschen, M.P., Franzen-Detrooz, E., Boniver, V., Boniver, J., Delvenne, P., 1998. Organotypic culture of HPV-transformed keratinocytes: a model for testing lymphocyte infiltration of (pre)neoplastic lesions of the uterine cervix. Virchows Arch. 432, 323-330.

Johnson, A.S., Maronian, N., Vieira, J., 2005. Activation of Kaposi's sarcomaassociated herpesvirus lytic gene expression during epithelial differentiation. J. Virol. 79, 13769-13777.

Kawada, M., Nagamori, S., Aizaki, H., Fukaya, K., Niiya, M., Matsuura, T., Sujino, H., Hasumura, S., Yashida, H., Mizutani, S., Ikenaga, H., 1998. Massive culture of human liver cancer cells in a newly developed radial flow bioreactor system: ultrafine structure of functionally enhanced hepatocarcinoma cell lines. In Vitro Cell Dev. Biol. Anim. 34, 109-115.

Kimpton, J., Emerman, M., 1992. Detection of replication-competent and pseudotyped human immunodeficiency virus with a sensitive cell line on the basis of activation of an integrated $\beta$-galactosidase gene. J. Virol. 66, 2232-2239.

Kumar, A.A., Rao, Y.U., Joseph, A.L., Mani, K.R., Swaminathan, K., 2002. Process standardization for optimal virus recovery and removal of substrate DNA and bovine serum proteins in Vero cell-derived rabies vaccine. J. Biosci. Bioeng. 94, 375-383.

Levine, W.C., Pope, V., Bhoomkar, A., Tambe, P., Lewis, J.S., Zaidi, A.A., Farshy, C.E., Mitchell, S., Talkington, D.F., 1998. Increase in endocervical CD4 lymphocytes among women with nonulcerative sexually transmitted diseases. J. Infect. Dis. 177, 167-174.

Levine, A., 2001. The origins of virology. In: Knipe, D.M., Howley, P.M. (Eds.), Fields Virology. Lippincott Williams \& Wilkins, Philadelphia, pp. 3-18.

Long, E.M., Martin Jr., H.L., Kreiss, J.K., Rainwater, S.M., Lavreys, L., Jackson, D.J., Rakwar, J., Mandaliya, K., Overbaugh, J., 2000. Gender differences in HIV-1 diversity at time of infection. Nat. Med. 6, 71-75.

Long, J.P., Pierson, S., Hughes, J.H., 1998. Rhinovirus replication in HeLa cells cultured under conditions of simulated microgravity. Aviat. Space Environ. Med. 69, 851-856.

Maher, D., Wu, X., Schacker, T., Horbul, J., Southern, P., 2005. HIV binding, penetration, and primary infection in human cervicovaginal tissue. Proc. Natl. Acad. Sci. U.S.A. 102, 11504-11509.

Margolis, L.B., Fitzgerald, W., Glushakova, S., Hatfill, S., Amichay, N., Baibakov, B., Zimmerberg, J., 1997. Lymphocyte trafficking and HIV infection of human lymphoid tissue in rotating wall vessel bioreactor. AIDS Res. Human Retroviruses 13, 1411-1420.

Mason, B., Ghanee, N., Haigh, W.G., Lee, S.P., Oda, D., 1999. Effect of vitamin A, C and $\mathrm{E}$ on normal and HPV-immortalized human oral epithelial cells in culture. Anticancer Res. 19, 5469-5474.

McLaughlin-Drubin, M.E., Wilson, S., Mullikin, B., Suzich, J., Meyers, C., 2003. Human papillomavirus type 45 propagation, infection, and neutralization. Virology 312, 1-7.

McLaughlin-Drubin, M.E., Christensen, N.D., Meyers, C., 2004. Propagation, infection, and neutralization of authentic HPV16 virus. Virology 322, 213-219.

Meyers, C., Frattini, M.G., Hudson, J.B., Laimins, L.A., 1992. Biosynthesis of human papillomavirus from a continuous cell line upon epithelial differentiation. Science 257, 971-973.

Meyers, C., Mayer, T.J., Ozbun, M.A., 1997. Synthesis of infectious human papillomavirus type 18 in differentiating epithelium transfected with viral DNA. J. Virol. 71, 7381-7386.

Meyers, C., Mane, M., Kokorina, N., Alam, S., Hermonat, P.L., 2000. Ubiquitous human adeno-associated virus type 2 autonomously replicates in differentiating keratinocytes of a normal skin model. Virology 272, $338-346$
Meyers, C., Bromberg-White, J.L., Zhang, J., Kaupas, M.E., Bryan, J.T., Lowe, R.S., Jansen, K.U., 2002. Infectious virions produced from a human papillomavirus type 18/16 genomic DNA chimera. J. Virol. 76, 4723-4733.

Meyers, C., Andreansky, S.S., Courtney, R.J., 2003. Replication and interaction of herpes simplex virus and human papillomavirus in differentiating host epithelial tissue. Virology 315, 43-55.

Miller, C.J., Vogel, P., Alexander, N.J., Sutjipto, S., Hendrickx, A.G., Marx, P.A., 1992. Localization of SIV in the genital tract of chronically infected female rhesus macaques. Am. J. Pathol. 141, 655-660.

Miller, C.J., 1998. Host and viral factors influencing heterosexual HIV transmission. Rev. Reprod. 3, 42-51.

Montagnon, B., Vincent-Falquet, J.C., Fanget, B., 1983. Thousand litre scale microcarrier culture of Vero cells for killed polio virus vaccine. Promising results. Dev. Biol. Stand. 55, 37-42.

Montagnon, B.J., Fanget, B., Nicolas, A.J., 1981. The large-scale cultivation of VERO cells in micro-carrier culture for virus vaccine production. Preliminary results for killed poliovirus vaccine. Dev. Biol. Stand. 47, 55-64.

Montagnon, B.J., 1985. Inactivated polio vaccine: industrial production from micro-carrier Vero cells culture. Trop. Geogr. Med. 37, S40-S41.

Montagnon, B.J., 1989. Polio and rabies vaccines produced in continuous cell lines: a reality for Vero cell line. Dev. Biol. Stand. 70, 27-47.

Montagnon, B.J., Vincent-Falquet, J.C., 1998. Experience with the Vero cell line. Dev. Biol. Stand. 93, 119-123.

Moscona, A., 1952. Cell suspensions from organ rudiments of chick embryos. Exp. Cell Res. 3, 535-539.

Moscona, A., 1961. Rotation-mediated histogenetic aggregation of dissociated cells. A quantifiable approach to cell interactions in vitro. Exp. Cell Res. 22, 455-475.

Mueller-Klieser, W., 1997. Three-dimensional cell cultures: from molecular mechanisms to clinical applications. Am. J. Physiol. 273, C1109-C1123.

Noya, F., Balague, C., Banerjee, N.S., Curiel, D.T., Broker, T.R., Chow, L.T., 2003. Activation of adenovirus early promoters and lytic phase in differentiated strata of organotypic cultures of human keratinocytes. J. Virol. 77, 6533-6540.

Nuovo, G.J., Forde, A., MacConnell, P., Fahrenwald, R., 1993. In situ detection of PCR-amplified HIV-1 nucleic acids and tumor necrosis factor cDNA in cervical tissues. Am. J. Pathol. 143, 40-48.

Ozbun, M.A., Meyers, C., 1996. Transforming growth factor beta1 induces differentiation in human papillomavirus-positive keratinocytes. J. Virol. 70, 5437-5446.

Patterson, B.K., Landay, A., Andersson, J., Brown, C., Behbahani, H., Jiyamapa, D., Burki, Z., Stanislawski, D., Czerniewski, M.A., Garcia, P., 1998. Repertoire of chemokine receptor expression in the female genital tract: implications for human immunodeficiency virus transmission. Am. J. Pathol. 153, 481-490.

Patterson, B.K., Landay, A., Siegel, J.N., Flener, Z., Pessis, D., Chaviano, A., Bailey, R.C., 2002. Susceptibility to human immunodeficiency virus-1 infection of human foreskin and cervical tissue grown in explant culture. Am. J. Pathol. 161, 867-873.

Pomerantz, R.J., de la Monte, S.M., Donegan, S.P., Rota, T.R., Vogt, M.W., Craven, D.E., Hirsch, M.S., 1988. Human immunodeficiency virus (HIV) infection of the uterine cervix. Ann. Intern. Med. 108, 321-327.

Pope, M., 1999. Mucosal dendritic cells and immunodeficiency viruses. J. Infect. Dis. 179 (Suppl. 3), S427-S430.

Regnier, M., Desbas, C., Bailly, C., Darmon, M., 1988. Differentiation of normal and tumoral human keratinocytes cultured on dermis: reconstruction of either normal or tumoral architecture. In Vitro Cell Dev. Biol. 24, 625-632.

Renard, I., Mezzanzanica, D., Canevari, S., Ferrini, S., Boniver, J., Delvenne, P., Jacobs, N., 2002. Anti-CD3/anti-epidermal growth factor receptorbispecific antibody retargeting of lymphocytes against human neoplastic keratinocytes in an autologous organotypic culture model. Am. J. Pathol. 160, 113-122.

Sahai, E., Marshall, C.J., 2003. Differing modes of tumour cell invasion have distinct requirements for Rho/ROCK signalling and extracellular proteolysis. Nat. Cell Biol. 5, 711-719. 
Sen, E., McLaughlin, M.A., Meyer, C., 2004. Efficacy of two commercial preparations of interferon- $\alpha$ on human papillomavirus replication. Anticancer Res. 25, 765-778.

Sista, P.R., Melby, T., Davison, D., Jin, L., Mosier, S., Mink, M., Nelson, E.L., DeMasi, R., Cammack, N., Salgo, M.P., Matthews, T.J., Greenberg, M.L., 2004. Characterization of determinants of genotypic and phenotypic resistance to enfuvirtide in baseline and on-treatment HIV-1 isolates. AIDS 18, 1787-1794.

Sivard, P., Berlier, W., Picard, B., Sabido, O., Genin, C., Misery, L., 2004. HIV-1 infection of Langerhans cells in a reconstructed vaginal mucosa. J. Infect. Dis. 190, 227-235.

Snoeck, R., Holy, A., Dewolf-Peeters, C., Van Den, O.J., De Clercq, E., Andrei, G., 2002. Antivaccinia activities of acyclic nucleoside phosphonate derivatives in epithelial cells and organotypic cultures. Antimicrob. Agents Chemother. 46, 3356-3361.

Steenbergen, R.D., Parker, J.N., Isern, S., Snijders, P.J., Walboomers, J.M., Meijer, C.J., Broker, T.R., Chow, L.T., 1998. Viral E6-E7 transcription in the basal layer of organotypic cultures without apparent p21cip1 protein precedes immortalization of human papillomavirus type 16- and 18-transfected human keratinocytes. J. Virol. 72, 749-757.

Sugawara, K., Nishiyama, K., Ishikawa, Y., Abe, M., Sonoda, K., Komatsu, K., Horikawa, Y., Takeda, K., Honda, T., Kuzuhara, S., Kino, Y., Mizokami, H., Mizuno, K., Oka, T., Honda, K., 2002. Development of Vero cell-derived inactivated Japanese encephalitis vaccine. Biologicals 30, 303-314.

Sutherland, R.M., McCredie, J.A., Inch, W.R., 1971. Growth of multicell spheroids in tissue culture as a model of nodular carcinomas. J. Natl. Cancer Inst. 46, 113-120.

Sutherland, R.M., 1988. Cell and environment interactions in tumor microregions: the multicell spheroid model. Science 240, 177-184.

Syrjanen, S., Mikola, H., Nykanen, M., Hukkanen, V., 1996. In vitro establishment of lytic and nonproductive infection by herpes simplex virus type 1 in three-dimensional keratinocyte culture. J. Virol. 70, 6524-6528.

Thach, D.C., Stenger, D.A., 2003. Effects of collagen matrix on Sindbis virus infection of BHK cells. J. Virol. Methods 109, 153-160.
Trabelsi, K., Rourou, S., Loukil, H., Majoul, S., Kallel, H., 2006. Optimization of virus yield as a strategy to improve rabies vaccine production by Vero cells in a bioreactor. J. Biotechnol. 121, 261-271.

Vincent-Falquet, J.C., Peyron, L., Souvras, M., Moulin, J.C., Tektoff, J., Patet, J., 1989. Qualification of working cell banks for the Vero cell line to produce licensed human vaccines. Dev. Biol. Stand. 70, 153-156.

Visalli, R.J., Courtney, R.J., Meyers, C., 1997. Infection and replication of herpes simplex virus type 1 in an organotypic epithelial culture system. Virology 230, 236-243.

Weaver, V.M., Petersen, O.W., Wang, F., Larabell, C.A., Briand, P., Damsky, C., Bissell, M.J., 1997. Reversion of the malignant phenotype of human breast cells in three-dimensional culture and in vivo by integrin blocking antibodies. J. Cell Biol. 137, 231-245.

Weiss, H.A., Quigley, M.A., Hayes, R.J., 2000. Male circumcision and risk of HIV infection in sub-Saharan Africa: a systematic review and metaanalysis. AIDS 14, 2361-2370.

WHO requirements for the use of animal cells as in vitro substrates for the production of biologicals (Requirements for Biological Substances No. 50), 1998. Biologicals 26, 175-193.

Wilson, J.L., Dollard, S.C., Chow, L.T., Broker, T.R., 1992. Epithelial-specific gene expression during differentiation of stratified primary human keratinocyte cultures. Cell Growth Differ. 3, 471-483.

Yokomizo, A.Y., Antoniazzi, M.M., Galdino, P.L., Azambuja Jr., N., Jorge, S.A., Pereira, C.A., 2004. Rabies virus production in high Vero cell density cultures on macroporous microcarriers. Biotechnol. Bioeng. 85, 506-515.

Yokoyama, M., Nakao, Y., Iwasaka, T., Pater, A., Sugimori, H., 2001. Retinoic acid and interferon-alpha effects on cell growth and differentiation in cervical carcinoma cell lines. Obstet. Gynecol. 98, 332-340.

Yokoyama, M., Noguchi, M., Nakao, Y., Pater, A., Iwasaka, T., 2004. The tea polyphenol, (-)-epigallocatechin gallate effects on growth, apoptosis, and telomerase activity in cervical cell lines. Gynecol. Oncol. 92, 197-204.

Zussman, A., Lara, L., Lara, H.H., Bentwich, Z., Borkow, G., 2003. Blocking of cell-free and cell-associated HIV-1 transmission through human cervix organ culture with UC781. AIDS 17, 653-661. 